\title{
Pemeriksaan Tekanan Darah dan Konseling Gizi pada Siswa-Siswi SMAN 1 Gerung
}

\author{
Junendri Ardian ${ }^{*}$, Baiq Fitria Rahmiati², M. Zulfikar Alfariki ${ }^{3}$, \\ Wiwin Lastyana ${ }^{4}$, Regina Pricilia Yunika ${ }^{5}$ \\ 1,2,3,4,5Universitas Bumigora, Mataram, Indonesia \\ *Corresponding Author: ardianjunendri@gmail.com
}

Info Artikel Diterima : 19/01/2022 Direvisi: 25/01/2022 Disetujui: 31/01/2022

\begin{abstract}
Hypertension or high blood pressure is a condition characterized by an increase in systemic arterial blood pressure above the threshold/normal value (Giles et al, 2009). Diseases and deaths that were initially dominated by infectious diseases turned into non-communicable diseases. Implementation In its implementation, the community service program is carried out with the following methods: $a$. Counseling was carried out by means of lectures using power points accompanied by pictures and discussions with students about the definition, classification, causes, risk factors, prevention and early management of hypertension in adolescents. $b$. Demonstration and examination of blood pressure and nutritional counseling. $C$. Weighing and height of students. Measuring the success of the activity, the service team measured the participants' knowledge before and after receiving counseling by distributing pre-test and post-test questionnaires. Conclusion: Before counseling the students' knowledge was $20.0 \%$ and after being given counseling there was an increase in knowledge to $90.0 \%$. This means that there is a significant change after being given counseling. The follow-up of the results of this community service is that similar blood pressure checks and nutritional counseling can be carried out in different places, so that more students know and understand about hypertension in adolescents.
\end{abstract}

Keywords: Blood Pressure, Hypertension, Nutrition Counseling.

\begin{abstract}
Abstrak. Hipertensi atau tekanan darah tinggi adalah suatu kondisi yang ditandai dengan kenaikan tekanan darah arterial sistemik diatas nilai ambang/normal. penyakit dan kematian yang mulanya didominasi oleh penyakit infeksi berubah menjadi penyakit tidak menular atau PTM. Dalam pelaksanannya, program pengabdian masyarakat dilaksanakan dengan metode sebagai berikut : a. Penyuluhan, dilakukan dengan ceramah dengan alat bantu berupa power point yang disertai dengan gambar dan juga dilakukan diskusi dengan Siswa-siswi tentang pengertian, klasifikasi, penyebab, faktor risiko, cara pencegahan dan manajemen awal hipertensi pada remaja. b. Demonstrasi dan pemeriksaan tekanan darah dan konseling gizi. c.Penimbangan berat badan dan tinggi badan terhadap siswa-siswi. Mengukur keberhasilan kegiatan, tim pengabdian mengadakan pengukuran pengetahuan peserta sebelum dan sesudah mendapatkan penyuluhan dengan membagikan kuisioner pre test dan post test. Simpulan: Sebelum dilakukan penyuluhan, pengetahuan siswa-siswi sejumlah $20.0 \%$ dan setelah diberikan penyuluhan terjadi peningkatan pengetahuan tersebut menjadi $90.0 \%$. berarti ada perubahan signifikan setelah diberikan penyuluhan. Tindak lanjut dari hasil pengabdian masyarakat ini adalah dapat dilakukannya pemeriksaan tekanan darah dan konseling gizi yang serupa di tempat yang berbeda, agar semakin banyak siswa-siswi mengetahui dan memahami mengenai hipertensi pada remaja.
\end{abstract}

Kata Kunci: Tekanan Darah, Hipertensi, Konseling Gizi.

How to Cite: Ardian, J., Rahmiati, B. F., Alfariki, M. Z., Lastyana, W., \& Yunika, R. P. (2022). Pemeriksaan Tekanan Darah dan Konseling Gizi pada Siswa-Siswi SMAN 1 Gerung. Prima Abdika: Jurnal Pengabdian Masyarakat, 2(1), 32-37. https://doi.org/10.37478/abdika.v2i1.1601

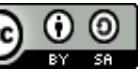

Copyright (c) 2022 Junendri Ardian, Baiq Fitria Rahmiati, M. Zulfikar Alfariki, Wiwin Lastyana, Regina Pricilia Yunika. This work is licensed under a Creative Commons Attribution-ShareAlike 4.0 International License.

\section{Pendahuluan}

Hipertensi atau tekanan darah tinggi adalah suatu kondisi yang ditandai dengan kenaikan tekanan darah arterial sistemik diatas nilai ambang/normal (Giles et al, 2009). penyakit dan kematian yang mulanya didominasi oleh penyakit infeksi berubah menjadi penyakit tidak menular atau PTM (Tifani, 2014). Salah satu PTM yang menjadi masalah serius belakangan ini adalah hipertensi yang sering disebut sebagai silent killer karena sering timbul tanpa disertai gejala. Umumnya hipertensi terjadi pada usia lanjut. Namun, beberapa penelitian menunjukkan bahwa hipertensi dapat muncul sejak remaja dan prevalensinya meningkat dalam beberapa tahun terakhir. Banyak 
pihak yang belum menyadari hal tersebut, bahwa hipertensi yang terjadi pada masa remaja akan berlanjut hingga usia dewasa dan meningkatkan risiko morbiditas dan mortalitas (Kurnianingtyas, 2016).

Klasifikasi tekanan darah pada remaja berbeda dengan tekanan darah pada dewasa karena tekanan darah meningkat seiring dengan bertambahnya usia. Klasifikasi tekanan darah pada remaja didasarkan pada kurva persentil yang mana remaja diklasifikasikan mengalami hipertensi dengan tekanan darah sebesar 130- 139/80-89 $\mathrm{mmHg}$ atau >95 persentil ditambah $11 \mathrm{mmHg}$ (Flynn JT et al. 2017). Hipertensi yang paling sering terjadi pada remaja adalah hipertensi esensial, yaitu hipertensi yang terjadi tanpa gejala dan banyak terdeteksi hanya saat pemeriksaan rutin (Saing JH, 2005).

Hipertensi pada remaja masuk ke dalam sepuluh penyakit kronis tertinggi di Amerika. Publikasi terbaru dari National Health and Nutrition Examination Survey (NHANES) menunjukkan bahwa satu dari 10 anak usia 8-17 tahun mengalami prehipertensi dan hipertensi (Kit BK, 2012). Berdasarkan data The Brazilian Study of Cardiovascular Risks in Adolescents (ERICA) prevalensi hipertensi pada remaja usia 12-17 tahun sebesar 9,6\% (Block KV, 2016). Kejadian hipertensi pada remaja juga ditemukan di Indonesia. Berdasarkan pedoman JNC VII 2003 dalam laporan Riskesdas tahun 2013 didapatkan prevalensi hipertensi terbatas pada usia 15-17 tahun secara nasional sebesar 5,3\% (laki-laki 6,0\% dan perempuan 4,7\%)(Riskesdas, 2013). Berdasarkan penelitian di Jakarta pada siswa SMA diperoleh sebanyak $15,5 \%$ remaja mengalami hipertensi (Nurmayanti, 2014). Begitu pula berdasarkan penelitian di Depok pada siswa SMA diperoleh 42,4\% remaja mengalami hipertensi (Angesti AN, 2018).

Hipertensi pada anak umumnya adalah hipertensi sekunder, berupa akibat dari penyakit parenkim ginjal sekitar 60-70\%, penyakit renovaskuler, feokromositoma, hipertiroid dan koarktasio aorta. Memasuki usia remaja, penyebab tersering adalah hipertensi primer dengan prevalensi sekitar 8595\% akibat gaya hidup yang tidak sehat (Sekarwana et al, 2011; Kliegmann et al, 2018). Munculnya masalah kesehatan pada anak tidak hanya disebabkan oleh kelalaian individu atau orang tua namun dapat pula disebabkan oleh ketidaktahuan masyarakat sebagai akibat kurangnya informasi yang benar mengenai suatu penyakit. Rendahnya pengetahuan tenaga kesehatan dan masyarakat tentang hipertensi merupakan penyebab utama tidak terkontrolnya tekanan darah, terutama pada pasien hipertensi di Asia. Pemberian informasi kesehatan diharapkan dapat mencegah dan mengurangi angka kejadian suatu penyakit dan sebagai sarana promosi kesehatan (Park et al, 2015).

Kegiatan pengabdian masyarakat ini sudah dilaksanakan di SMAN 1 Gerung dengan sasaran utama adalah Siswa- siswi kelas XII. Berdasarkan perubahan demografi pada masyarakat tanpa mempertimbangkan perubahan gaya hidup, diperkirakan penderita hipertensi akan meningkat dengan cepat dalam 10 tahun mendatang terutama pada negara berkembang. Dengan kegiatan ini diharapkan dapat meningkatkan kesadaran dan pengetahuan masyarakat khusunya Siswa- Siswi SMAN 1 Gerung Lombok Barat bahwa hipertensi tidak hanya terjadi pada dewasa saja, namun dapat juga terjadi pada anak-anak yang akan berlanjut hingga dewasa dengan risiko morbiditas dan mortalitas yang lebih tinggi bila tidak dideteksi sedini mungkin dan ditangani dengan baik (Luma dan Spiotta, 2006). Pengabdian masyarakat ini 
juga akan memberikan pemeriksaan kepada para siswa-siswi SMAN 1 Gerung mengenai pemeriksaan tekanan darah dan konseling Gizi yang sesuai dengan standar, menentukan klasifikasi hipertensi dan menatalaksana awalnya dengan baik.

\section{Metode Pelaksanaan}

Program pengabdian masyarakat ini melibatkan lima orang dosen dengan latar belakang ahli gizi yang telah mendapatkan sertifikasi kompetensi ahli gizi. Dalam pelaksanannya, program pengabdian masyarakat dilaksanakan dengan metode sebagai berikut :

1. Penyuluhan, dilakukan dengan ceramah dengan alat bantu berupa power point yang disertai dengan gambar dan juga dilakukan diskusi dengan Siswa-siswi tentang pengertian, klasifikasi, penyebab, faktor risiko, cara pencegahan hipertensi.

2. Demonstrasi dan pemeriksaan tekanan darah dan konseling gizi.

3. Penimbangan berat badan dan tinggi badan terhadap siswa-siswi.

\section{Hasil dan Pembahasan}

Pengabdian masyarakat ini dilaksanakan pada hari Senin tanggal 15 November 2021 di SMAN 1 Gerung Lombok Barat dengan jumlah peserta yang mengikuti kegiatan adalah 80 orang. Metode penyampaian materi menggunakan Power Point disertai dengan tanya jawab dan diskusi. Berdasarkan kegiatan tersebut terdapat kegiatan sebagai berikut: Adapun kegiatan yang dilakukan adalah:

a. Pembentukan satuan tugas pengabdian, pada kegiatan ini dilakukan koordinasi dengan pihak sekolah mengenai pemeriksaan dan konseling yang diadakan di sekolah.

b. Pembekalan tim pelaksana, pembekalan dilakukan oleh ketua pelaksana pengabdian berkaitan dengan pemeriksaan tekanan darah dan konseling gizi Sehingga berdasarkan hal tersebut, dibuatlah materi mengenai pencegahan hipertensi dan tata cara pengukuran tekanan darah.

c. Sebagian besar para Siswa-Siswi tidak mengetahui bahwa hipertensi dapat terjadi padaRemaja dan dapat berlanjut hingga usia dewasa.

d. Sebagian besar para peserta pengabdian dapat melakukan pengukuran tekanan darah dan konseling gizi.

Selanjutnya untuk mengukur keberhasilan kegiatan, tim pengabdian mengadakan pengukuran pengetahuan peserta sebelum dan sesudah mendapatkan penyuluhan dengan membagikan kuisioner pre test dan post test.

Berdasarkan Tabel 1 pada kegitan tersebut diperoleh hasil pengukuran antropometri untuk menentukan status gizi berdasarkan index massa tubuh (IMT) menunjukkan bahwa sebagian besar responden mempunyai ststus gizi lebih sejumlah 52,5 \%. Hasil pemeriksaan tekanan darat menunjukkan bahwa responden sebagian besar prehipertensi atau hipertensi tahap ringan sejumlah $62,5 \%$ dan hipertensi sejumlah $22,5 \%$. 
Prima Abdika: Jurnal Pengabdian Masyarakat 2(1), 2022, 32-37 Junendri Ardian, Baiq Fitria Rahmiati, M. Zulfikar Alfariki, Wiwin Lastyana, Regina Pricilia Yunika Pemeriksaan Tekanan Darah dan Konseling Gizi pada Siswa-Siswi SMAN 1 Gerung

Tabel 1. Distribusi Karakteritik Siswa -Siswi

\begin{tabular}{|c|c|c|}
\hline \multirow[t]{2}{*}{ Kategori } & \multicolumn{2}{|c|}{ Jumlah } \\
\hline & $\mathbf{n}$ & $\%$ \\
\hline \multicolumn{3}{|l|}{ 1. Satus Gizi (IMT) } \\
\hline$<18,5$ & 0 & 0 \\
\hline $18,5-23,5$ & 38 & 47.5 \\
\hline$>23,5$ & 42 & 52.5 \\
\hline \multicolumn{3}{|c|}{ 2. Hasil pengukuran tekanandarah } \\
\hline$<120 / 80$ mmHg(normal) & 12 & 15 \\
\hline $\begin{array}{l}\text { 120-138/80-90 mmHg } \\
\text { (prehipertensi) }\end{array}$ & 50 & 62.5 \\
\hline $\begin{array}{l}\text { 140-159/90-99 mmHG } \\
\text { (Hipertensi) }\end{array}$ & 18 & 22.5 \\
\hline Total & 80 & 100 \\
\hline
\end{tabular}

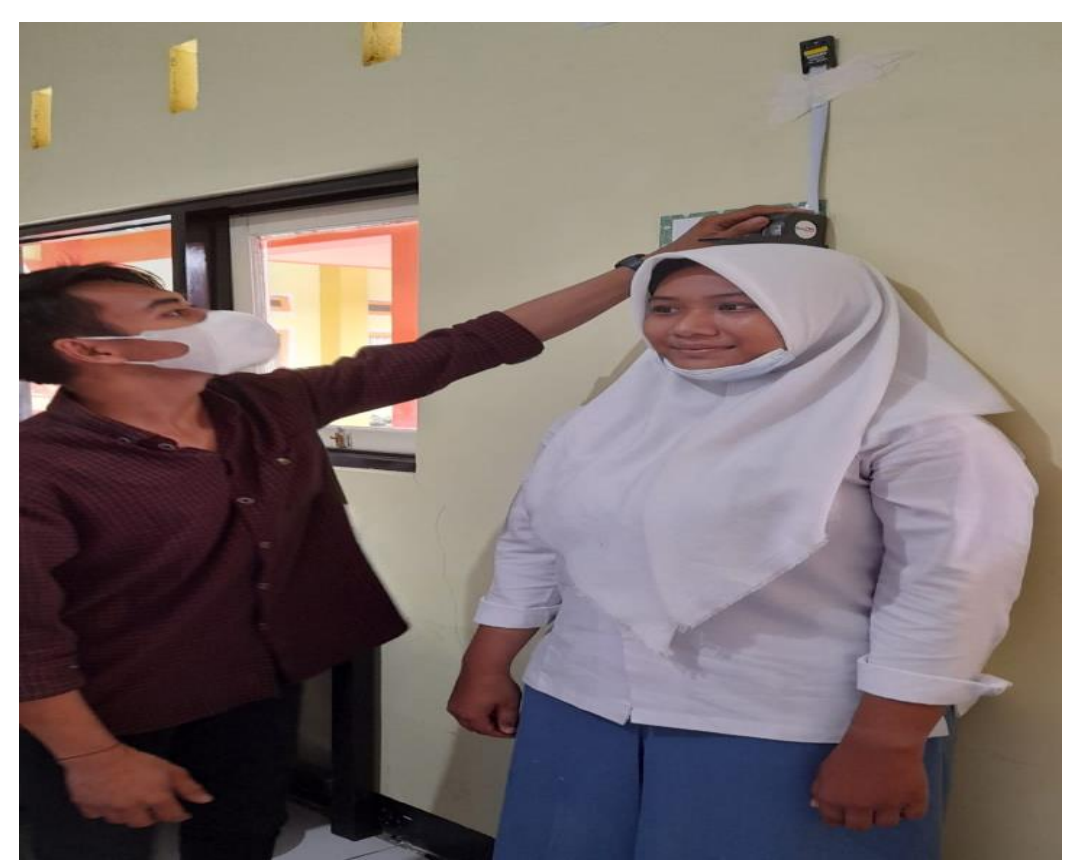

Gambar 1. Pengukuran Antropometri

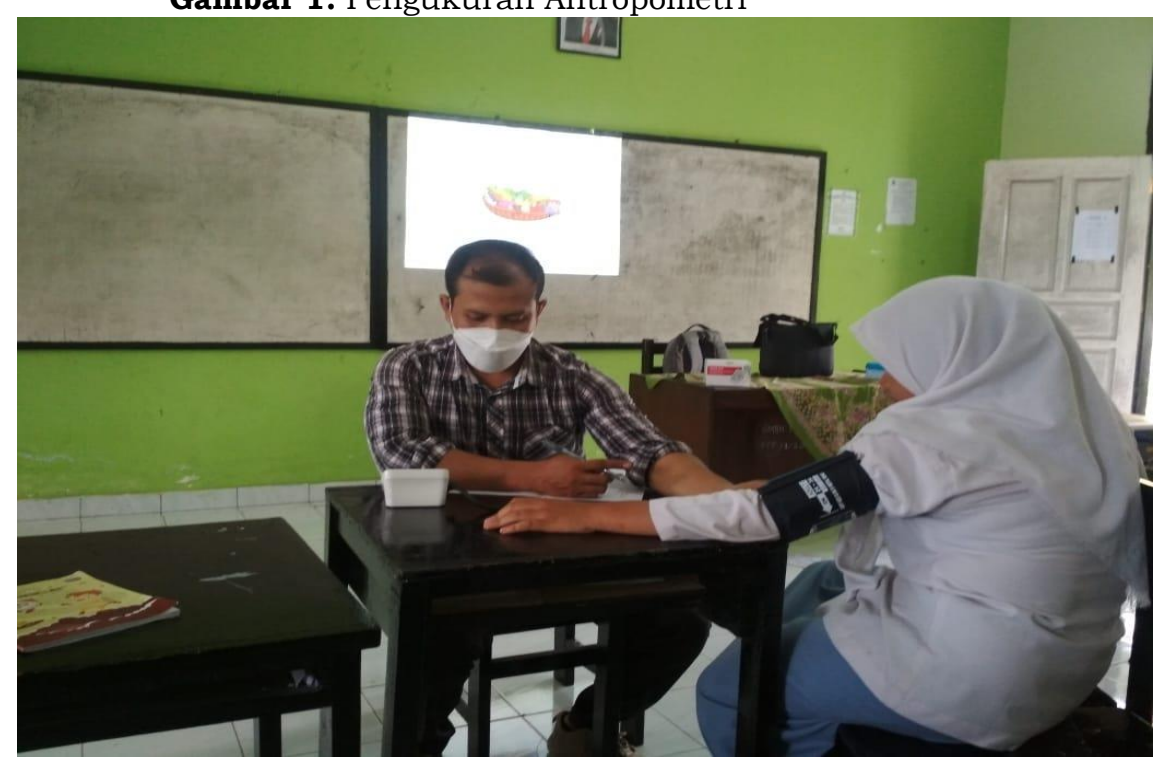

Gambar 2. Pemeriksan Tekanan Darah 
Tabel 2. Distribusi Pengetahuan siswa-siswi yang diberikan penyuluhan.

\begin{tabular}{lcrrr} 
& \multicolumn{2}{c}{ Jumlah } \\
& \multicolumn{2}{c}{ Pre Test } & \multicolumn{2}{c}{ Post Test } \\
& $\mathrm{n}$ & $\%$ & $\mathrm{n}$ & $\%$ \\
\hline Kurang & 64 & 80.0 & 8 & 10.0 \\
Baik & 16 & 20.0 & 72 & 90.0 \\
\hline Jumlah & 80 & 100 & 80 & 100
\end{tabular}

Berdasarkan Tabel 2 di atas menunjukkan bahwa sebelum dilakukan penyuluhan, pengetahuan siswa-siswi sejumlah $20.0 \%$ dan setelah diberikan penyuluhan terjadi peningkatan pengetahuan tersebut menjadi $90.0 \%$.

Pengetahuan merupakan hasil tahu yang terjadi setelah orang melakukan penginderaan terhadap suatu objek tertentu. Pengetahuan merupakan domain yang sangat penting untuk terbentuknya tindakan seseorang. Hasil penelitian membuktikan bahwa perilaku yang didasari oleh pengetahuan akan lebih langgeng dari pada yang tidak didasari pengetahuan (Notoatmodjo, 2003).

Hal ini juga sejalan dengan hasil penelitian dari Widyasari dkk (2010) terjadi peningkatan nilai rerata pengetahuan tentang edukasi gizi berkaitan dengan penyakit hipertensi setelah pemberian pendidikan dari 4,46 menjadi 13,97 .

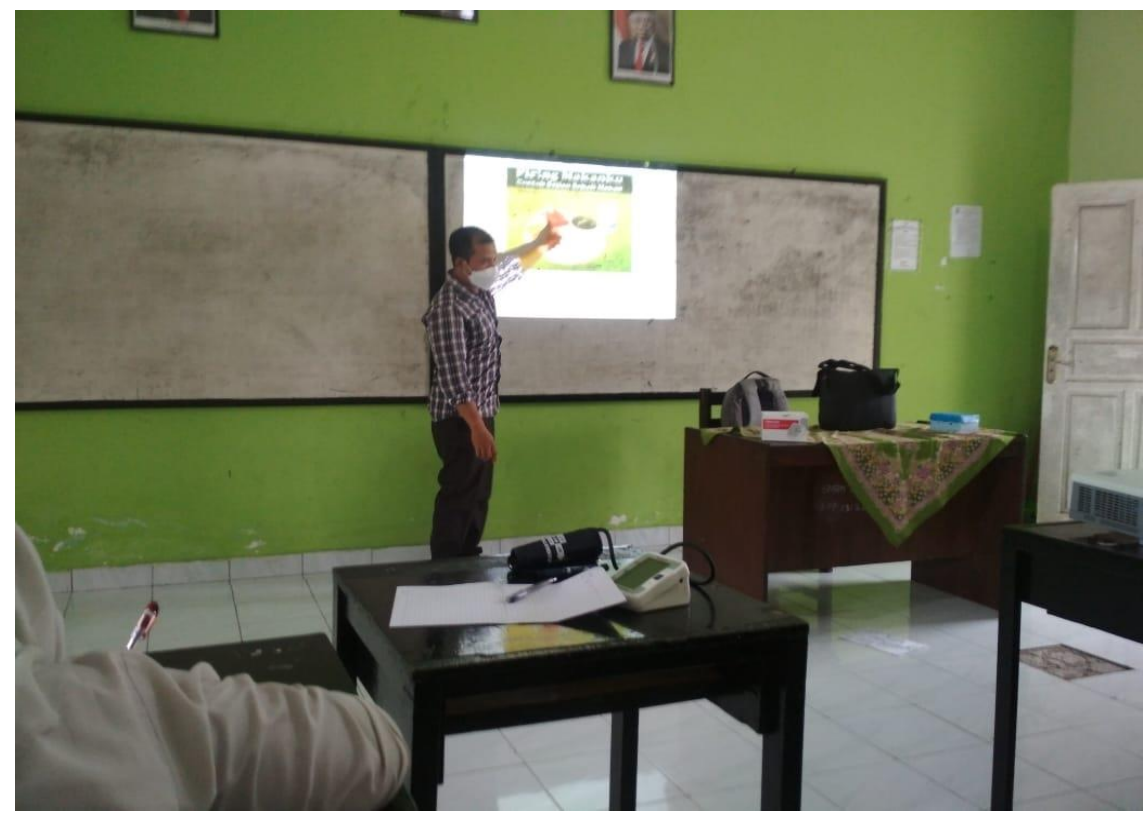

Gambar 3. Penyuluhan mengenai hipertensi dan gizi seimbang

\section{Simpulan dan Tindak Lanjut}

Sebelum dilakukan penyuluhan, pengetahuan siswa-siswi sejumlah $20.0 \%$ dan setelah diberikan penyuluhan terjadi peningkatan pengetahuan tersebut menjadi $90.0 \%$. berarti ada perubahan signifikan setelah diberikan penyuluhan. Tindak lanjut dari hasil pengabdian masyarakat ini adalah dapat dilakukannya pemeriksaan tekanan darah dan konseling gizi yang serupa di 
tempat yang berbeda, agar semakin banyak siswa-siswi mengetahui dan memahami mengenai hipertensi.

\section{Daftar Pustaka}

T. D. Giles, B. J. Materson, J. N. Cohn, and J. B. Kostis. 2009. "Defnition and classifcation of hypertension: an update," The Journal of Clinical Hypertension, vol. 11, no. 11, pp. 611-614.

Tifani Lasianjayani SM. Hubungan antara obesitas dan perilaku merokok terhadap Kejadian hipertensi. J Berk Epidemiol. 2014;2(3):286-96.

Kurnianingtyas BF, Suyatno, Kartasurya MI. Faktor Risiko kejadian hipertensi pada siswa sma di kota semarang Tahun 2016. J Kesehat Masy. 2017;5(2):70

Flynn JT, Ingelfinger JR, Redwine KM. Pediatric Hypertension [Internet]. Fourth Edi. Switzerland: Springer International Publishing; 2017. Diunduh dari: http://link. springer.com/10.1007/978-3-319-31420-4.

Saing JH. Hipertensi pada remaja. Sari Pediatr. 2005;6(4):159-65.

Kit BK, Kuklina E, Carroll MD, Ostchega Y, Freedman DS, Ogden CL . Prevalence of and trends in dyslipidemia and blood pressure among us children and adolescents, 1999- 2012. JAMA Pediatr. 2015;169(3):2729.

Bloch KV, Klein CH, Szklo M, Kuschnir MCC, De Azevedo Abreu G, Barufaldi LA, et al. ERICA: Prevalences of hypertension and obesity in brazilian adolescents. Rev Saude Publica. 2016;50(suppl 1):1s-12s.

Badan Penelitian dan Pengembangan Kesehatan. Riset kesehatan dasar 2013. Jakarta : Badan Penelitian dan Pengembangan Kesehatan ;2013. p1-384.

Nurmayanti. Studi Validasi Ukuran Antropometri Komposisi Lemak Tubuh terhadap Tekanan Darah pada Siswa-Siswi di SMAK Penabur Jakarta Tahun 2014. Universitas Indonesia; 2014.

Angesti AN, Triyanti, Sartika RAD. Riwayat Hipertensi Keluarga Sebagai Faktor Dominan Hipertensi pada Remaja Kelas XI SMA Sejahtera 1 Depok Tahun 2017. Bul Penelit Kesehat. 2018;46(1):1-10.

Sekarwana, N., Rachmadi, D. and Hilmanto, D. 2011.Unit Kerja Koordinasi Nefrologi Ikatan Dokter Anak Indonesia Konsensus Tatalaksana Hipertensi pada Anak, UKKNefrologi.

Kliegman R, Behrman R, Jenson H, Stanton B. Nelson Textbook of Pediatrics. $18^{\text {th }}$ ed.Elsevier,Sounders.2018

Parks, E. P., Maqbool, A., Shaikhkhalil, A., Groleau, V., Dougherty, K. A., \& Stallings, V. A. 2016. Nutritional Requirements. In Nelson Textbook of Pediatrics (pp. 269, 273,281). Elsevier.

Luma, G. B., \& Spiotta, R. T. 2006. Arterial hypertension in children and adolescents. Casopis Lekaru Ceskych, 145(8), 625-6

Notoatmodjo, S. 2003. Pendidikan dan Perilaku Kesehatan. Jakarta: Rineka Cipta.

Widyasari DA dan Candasari A (2010) . Peningkatan Pengetahuan tentang Hipertensi Lansia pada Posyandu Dukuh Gantungan Desa MakamHaji Kartasuro Sukoharjo. WARTA, Vol .13, No.1,: 28 - 36 ISSN 1410-9344. 